\title{
Self-reported risk behaviors among offender motorcyclists in Ahvaz City
}

Fereshteh Zamani-Alavijeh ${ }^{1}$, Nasim Narimani ${ }^{2}$, Ali Montazeri ${ }^{3}$, Ahmad Fakhri ${ }^{4}$, Morteza Mansourian ${ }^{5}$, Amir Shafiee $^{6}$, Akbar Babaei Heydarabadi ${ }^{7}$

${ }^{1}$ Ph.D. of Health Education, Assistant Professor, Department of Health Education and promotion, School of Health, Isfahan University of Medical Sciences, Isfahan, Iran

${ }^{2}$ M.Sc. Student of Health Education, Faculty of Health, Department of Public Health, Ahvaz Jundishapur University of Medical Sciences, Ahvaz, Iran

${ }^{3}$ Ph.D., Professor, Mental Health Research Group, Health Metrics Research Centre, Iranian Institute for Health Sciences Research, ACECR, Tehran, Iran

${ }^{4}$ Ph.D. of Psychiatric, Assistant Professor, Department of Psychiatric, Faculty of Medicine, Ahvaz Jundishapur University of Medical Sciences, Ahvaz, Iran

${ }^{5}$ Ph.D. of Health Education, Assistant Professor, Department of Health Education, School of Health, Iran University of Medical Sciences, Tehran, Iran

${ }^{6} \mathrm{Ph} . \mathrm{D}$. Student, Department of Industrial Engineering, Yazd University, Yazd, Iran

${ }^{7}$ Ph.D. of Health Education and Promotion, Department of Public Health, Students' Research Committee, Faculty of Health, Shahid Beheshti University of Medical Sciences, Tehran, Iran

\section{Type of article: Original}

\begin{abstract}
Introduction: Road traffic accidents are among the most critical public health issues. Many people die on the roads each day and tens of millions sustain nonfatal injuries. The aim of this study is to describe the high-risk behaviors of motorcyclists in which police had to confiscate their motorcycles.

Methods: This cross-sectional study was carried out on 240 motorcyclists in Iran from December 2010 to February 2011. A researcher-created questionnaire was used to collect data on self-reported high-risk behaviors, including passing the crossroads without considering the traffic light, refusing to wear a helmet, performing stunts in the street, and driving in the opposite direction. The collected data was descriptively analyzed.

Results: The mean age of motorcyclists was 29.3 years $(\mathrm{SD}=8.26)$. Twenty-six percent $(\mathrm{n}=62)$ of the participants did not have a motorcycle driver's license. The analysis of risk behaviors showed that $60.8 \%(\mathrm{n}=146)$ of the motorcycle drivers usually passed crossroads without considering the traffic light and $20.8 \%(n=50)$ performed stunts in the street.

Conclusions: This study indicates that the prevalence of high-risk behaviors among motorcyclists is significant. Health education interventions may inhibit these behaviors, thus reducing the risk of injuries.

Keywords: high-risk behavior, offender motorcyclist, traffic accident
\end{abstract}

\section{Introduction}

Road traffic accidents are among the most critical public health issues (1-3). More than 3000 people die each day on the roads and tens of millions sustain nonfatal injuries $(2,4,5)$. Road traffic systems are dangerous systems that people deal with on a daily basis (6). In this dangerous and complex system, motorcycle drivers are a priority group to protect from injuries and death in traffic accidents in Iran (7) and other countries (8-10). The World Health Organization reported that, on busy roads, motorcyclists and pedestrians are particularly susceptible to traffic injuries (11). Driving a motorcycle is related to the high risk of death and injury $(12,13)$, and, in many countries, the number of injured or killed during motorcycle and bicycle riding is rapidly rising (14). The risk of death for two-

\section{Corresponding author:}

Professor Dr. Ali Montazeri, Mental Health Research Group, Health Metrics Research Centre, Iranian Institute for Health Sciences Research, ACECR, Tehran, Iran. Tel: +98.2166951877, E-mail: montazeri@acecr.ac.ir

Received: October 09, 2015, Accepted: November 05, 2015, Published: November 2015

iThenticate screening: October 26, 2015, English editing: November 07, Quality control: November 08, 2015

(C) 2015 The Authors. This is an open access article under the terms of the Creative Commons Attribution-NonCommercialNoDerivs License, which permits use and distribution in any medium, provided the original work is properly cited, the use is non-commercial and no modifications or adaptations are made. 
wheel drivers is higher than that in automobiles (15). Study results indicate that motorcyclists' behaviors are typically related to their injuries. Some motorcycle riders put themselves and others at risk (16). Results of a selfreported cross-sectional study revealed that motorcycle riders with a history of injuries were less likely to wear helmets or any other protective equipment (17). Therefore, it is suggested to conduct more studies to understand these behaviors, find ways for its modification, and to evaluate the effectiveness of current policies (18). It is believed that there are enormous gaps in the researches about behavioral theories and models applied to unintentional injury prevention (19). Increasing knowledge about motorcyclists' accident-related risk behaviors is thus an important way to set goals in designing intervention programs and improving road safety. However, there is little recognition of this problem (7). A qualitative study, which was conducted in Iran, indicated that there are seven injury-related risk behaviors among motorcyclists, including performing stunts in the street, disobeying traffic rules, riding after drug or alcohol use, riding without qualifications, not using a helmet while riding a motorcycle, illegally transporting pillion passengers, and transporting cargo (7). Thus, studies regarding types and frequency of these risk behaviors are necessary. Previous studies suggest that it could be useful to indicate the behavioral determinants that increase people's vulnerability to injuries. Such information is likely to shed light on the cause of road traffic injuries among motorcyclists (20). Previous studies have shown that accidents mostly happen to those who previously experienced them, and WHO reported that nearly a quarter of the victims of road traffic accidents requiring admission to a hospital have suffered a traumatic head injury (11). Most of these riders failed to utilize preventive behaviors such as wearing a helmet. The best strategy for reducing such injuries is to correct those behaviors. Tougher traffic law enforcement to save riders and their pillion passengers has been recommended. A motorcycle driver's license and other safe behaviors should be enforced under stronger regulations $(19,21)$. In Iran, obeying the current traffic laws, including helmet wearing and having a motorcycle driver's license, is mandatory for all motorcyclists (22), but the prevalence of voluntary helmet use is low (23). A study by Paravar et al. showed just $3.1 \%$ of injured motorcyclists had used a helmet (4) and most road traffic injuries among motorcyclists are caused by preventable factors. It is seen that law enforcement and punishment or fear of receiving a fine do not always result in corrected behavior (22); some studies have shown that accidents mostly happen to those who had a previous experience. More studies are necessary to understand these behaviors. Thus, which risk behaviors were enacted by riders whose motorcycles have been confiscated by police officers and have paid fines and penalties for the second or third time? This study was carried out to address the risk behaviors among motorcycle riders who attempted offenses and their motorcycles had been re-confiscated by police officers.

\section{Material and Methods}

This cross-sectional study was conducted to describe injury-related risk behaviors among motorcyclists whose motorcycles were confiscated by police officers in Ahvaz (a city in the south of Iran) from December 2010 to February 2011. The sample was recruited from the Motorcycle Clearance Center of Police Organization. The inclusion criteria were: 1) riding while police have booked their motorcycle; 2) the motorcycle had been booked previously at least one time; 3 ) the motorcycle had been booked no more than two days prior to interviews; 4) being literate (to be able to read and write); and 5) being interested in participating in the study. In the Mazloomy study (24), the prevalence of risky behavior (lack of helmet use) was $\mathrm{P}=0.1, \alpha=0.5$, and $\mathrm{d}=0.4$. Thus, sample size was calculated at 216. Those who were discharged with their motorcycle, after coordination with the police and obtaining verbal consent, were interviewed. Based on a previous qualitative research (7), a questionnaire, which included items regarding risk behaviors, was used to collect data. The risk behaviors were: 1) not wearing a helmet; 2) performing stunts; 3) disobeying traffic rules, including moving in the opposite direction of street, passing without obeying traffic lights, and riding with exceeding the speed limit; 4) illegally transporting passengers; 5) illegally transporting cargo; and 6) riding a damaged motorcycle. The behaviors were measured using five-point scales (always, often, sometimes, seldom, and never).

Regarding the research ethics, the Motorcycle Clearance Center and Police Center of Ahvaz approved the study to provide opportunities for the informed choices; one of us (NN) explained the study objectives to the motorcyclists and those who volunteered for the study. The volunteer motorcyclists signed a consent form. Data were analyzed using a descriptive fashion. This included reporting of numbers and frequencies.

\section{Results}

\subsection{Characteristics of riders}

In all, 240 motorcyclists were approached and entered into the study. The mean age of the motorcyclists was 29.33 $(\mathrm{SD}=8.26)$ years (ranging from 16 to 59$)$ and $62.1 \%(\mathrm{n}=149)$ were married. Most riders $(41.7 \%)$ had a secondary education. Sixty-two riders $(25.8 \%)$ did not have a driver's license and 82 riders $(35 \%)$ were not the owners of the 
booked motorcycles, but they were arrested while riding them. Thirty-five percent of motorcyclists had at least one motorcycle accident in the recent year (Table 1).

Table 1. The characteristics of offender motorcyclists $(n=240)$

\begin{tabular}{|l|l|l|l|}
\hline Characteristics & Mean (SD) & n & $\%$ \\
\cline { 2 - 4 } & Range & $29.33(8.26)$ & - \\
\hline \multirow{3}{*}{ Education level } & Illiterate/Primary & $16-59$ & - \\
\cline { 2 - 4 } & Secondary school & 9 & 3.7 \\
\cline { 2 - 4 } & Higher education & 61 & 70.9 \\
\hline \multirow{2}{*}{ Marital status } & Single & 91 & 25.4 \\
\cline { 2 - 4 } & Married & 149 & 37.9 \\
\hline \multirow{2}{*}{ Riding license } & Yes & 178 & 62.1 \\
\cline { 2 - 4 } & No & 62 & 72.2 \\
\hline \multirow{3}{*}{ Motorcycle ownership } & Yes & 156 & 25.8 \\
\cline { 2 - 4 } & No & 84 & 35 \\
\hline \multirow{2}{*}{$\begin{array}{l}\text { Experience of accident } \\
\text { in recent year }\end{array}$} & None & 154 & 66.4 \\
\cline { 2 - 4 } & Once & 57 & 23.7 \\
\cline { 2 - 4 } & Twice & 17 & 2.0 \\
\cline { 2 - 4 } & Three times or more & 12 & 2.9 \\
\hline
\end{tabular}

\subsection{Risk behaviors}

Overall, $60.8 \%$ of riders reported that they passed traffic lights without considering the traffic red light during the recent week. Only $14.2 \%(\mathrm{n}=34)$ of riders reported that they did not ride a motorcycle without using a helmet. More than $20 \%$ performed stunts, including wheel spins and wheel stands, during the recent weeks. More than $95 \%$ of motorcyclists reported that they illegally transported passengers and, similarly, more than $87 \%$ reported that they illegally transported cargo. Detailed results are shown in Table 2.

Table 2. Risky behaviors committed by offender motorcyclists $(n=240)$

\begin{tabular}{|c|c|c|c|c|c|c|c|}
\hline Risky behavior & $\begin{array}{l}\text { Never, } \\
\mathrm{n}(\%)\end{array}$ & $\begin{array}{l}\text { Seldom, } \\
\mathrm{n}(\%)\end{array}$ & $\begin{array}{l}\text { Sometimes, } \\
\mathrm{n}(\%)\end{array}$ & $\begin{array}{l}\text { Often, } \\
\mathrm{n}(\%)\end{array}$ & $\begin{array}{l}\text { Always, } \\
\mathrm{n}(\%)\end{array}$ & Sum* & $\operatorname{Rank}^{* *}$ \\
\hline $\begin{array}{l}\text { Passing crosses without } \\
\text { considering the traffic red light }\end{array}$ & $\begin{array}{l}94 \\
(39.2)\end{array}$ & $\begin{array}{l}63 \\
(26.3)\end{array}$ & $61(25.4)$ & $\begin{array}{l}18 \\
(7.5)\end{array}$ & $4(1.7)$ & 945 & 5 \\
\hline Performing stunts & $\begin{array}{l}189 \\
(78.75)\end{array}$ & $\begin{array}{l}25 \\
(10.4)\end{array}$ & $15(6.3)$ & $7(2.9)$ & $4(1.7)$ & 1159 & 9 \\
\hline Moving in the opposite direction & $\begin{array}{l}104 \\
(43.3)\end{array}$ & $\begin{array}{l}69 \\
(28.8)\end{array}$ & $47(19.6)$ & $\begin{array}{l}16 \\
(6.7)\end{array}$ & $4(1.7)$ & 1108 & 8 \\
\hline Not wearing a helmet & $\begin{array}{l}55 \\
(22.9)\end{array}$ & $\begin{array}{l}82 \\
(34.2)\end{array}$ & $52(21.7)$ & $\begin{array}{l}17 \\
(7.1)\end{array}$ & $34(14.2)$ & 973 & 7 \\
\hline $\begin{array}{l}\text { Riding motorcycle after consuming } \\
\text { alcohol }\end{array}$ & $\begin{array}{l}220 \\
(91.7)\end{array}$ & $4(1.7)$ & $13(5.4)$ & $1(0.4)$ & $2(0.8)$ & 827 & 3 \\
\hline $\begin{array}{l}\text { Riding motorcycle after using } \\
\text { recreational drugs }\end{array}$ & $\begin{array}{l}220 \\
(91.7)\end{array}$ & $4(1.7)$ & $13(5.4)$ & $1(0.4)$ & $2(0.8)$ & 1159 & 10 \\
\hline $\begin{array}{l}\text { Using cell phone while riding } \\
\text { motorcycle }\end{array}$ & $\begin{array}{l}69 \\
(28.8)\end{array}$ & $\begin{array}{l}83 \\
(34.6)\end{array}$ & $68(28.3)$ & $\begin{array}{l}16 \\
(6.7)\end{array}$ & $4(1.7)$ & 917 & 4 \\
\hline Illegally transport passenger & $10(4.2)$ & $\begin{array}{l}25 \\
(10.4)\end{array}$ & $107(44.6)$ & $\begin{array}{l}72 \\
(30.0)\end{array}$ & $26(10.9)$ & 686 & 1 \\
\hline Illegally transport cargos & $\begin{array}{l}31 \\
(12.9)\end{array}$ & $\begin{array}{l}46 \\
(19.2)\end{array}$ & $114(47.5)$ & $\begin{array}{l}33 \\
(13.8)\end{array}$ & $16(6.7)$ & 763 & 2 \\
\hline Riding a damaged motorcycle & $\begin{array}{l}93 \\
(38.8)\end{array}$ & $\begin{array}{l}69 \\
(28.8)\end{array}$ & $62(25.8)$ & $\begin{array}{l}13 \\
(5.4)\end{array}$ & $3(1.2)$ & 956 & 6 \\
\hline
\end{tabular}

*Total scores for each risk behavior (Never: 5, Seldom: 4, Sometimes: 3, Often: 2, Always: 1), **Ranking of risky behaviors (1: most, 10: least). 


\section{Discussion}

This study reported on risk behaviors among offender motorcyclists. The findings indicate that some riders were in their thirties and, in fact, were not joy riders, as typically seen in teenagers. People in this age group, generally, are married and responsible for caring for a family; thus, severe injuries and deaths among this population might cause extra costs and burdens to families and the community $(23,25)$. Younger motorcyclists believed that risky riding is a way to achieve enjoyment and increase the attention and acclamation of their friends (26). This study shows that $35 \%$ of riders did not have a driver's license. In a cross-sectional study on 299 commercial motorcyclists in Igboora, mean age was $27.4 \pm 7.4$ years and $61.2 \%$ had a driver's license (27). It seems that not only do traffic police take this problem seriously but that family members should be educated by public media to prevent loved ones from riding a motorcycle without having the proper license. Passing the cross roads without considering the red light also was reported by more than $50 \%$ of the riders. This is a serious problem for motorcyclists and for pedestrians. Perhaps the police should take more responsibility to tackle this problem because this usually happens in front of police. The Iranian parliament approved a new bill for two-wheel drivers, which mandated using standard helmets. The finding from this study indicated that police confiscated $85 \%$ of riders because they were still not using a helmet. In some studies, all (100\%) motorcyclists did not use any helmet (27). In a previous study in Iran, only $10 \%$ of motorcyclists used a standard helmet (28). However, unhelmeted motorcyclists are more likely to suffer fatal head trauma than helmeted riders when involved in a road traffic accident (26). The results also demonstrated that $70 \%$ of riders had performed stunts during the week before the study. Stunt behaviors such as wheel spins and wheel stands usually are seen among teenagers or youngsters, but, in this study, even married adults performed such behaviors. It seems we need more investigations to find out what really causes riders perform these behaviors. As suggested, the enormous gaps exist in the research on the behavior theories and models applied to prevent the risks (19). Studies have shown that two-wheel drivers face higher risks of death and injury $(12,13)$ and some riders not only put themselves at risk but others, particularly pedestrians $(11,16)$. We have to design education programs for riders and pedestrians. Overall results of this study showed that not using a standard helmet, passing red lights, not having a driver's license, wheel spinning and wheel standing, riding in the opposite direction, illegally transport passengers and cargos, riding and exceeding the speed limit are the main risk behaviors among riders whose motorcycles were confiscated by police. While a descriptive study may limit the identity of factors related to risk behaviors, in this paper, researchers were not aiming to identify a list of reasons that could influence behaviors of motorcyclists, as is the case in analytical or interventional research. Instead, the goal of the present study is to gain an understanding of the frequency of risk behaviors among offending motorcyclists.

\section{Conclusions}

The findings in this study indicate that risk behaviors among motorcyclists are relatively high. For preventing risk behaviors and related traffic injuries, further studies are needed in order to identify the causes of these behaviors among Iranian motorcyclists. Findings of studies in other communities could not be used directly in Iran because each country has its own problems in traffic culture, as noted by Özkan (29). Indeed, designing community-based health education interventions seem necessary to prevent risk of injuries and deaths among this population.

\section{Acknowledgments:}

Support for this paper came from research project no. 89s33 of the validity of Technology and Research Deputy of Ahvaz Jundishapur University of Medical Sciences. The authors also warmly appreciate Jundishapur University of

Medical Sciences, Ahvaz, Iran, for supporting this study. In addition, thanks to the Health Center staff of the Motorcycle Clearance Center and Police Center of Ahvaz and also motorcyclists for their assistance in carrying out this study.

\section{Conflict of Interest:}

There is no conflict of interest to be declared.

\section{Authors' contributions:}

All authors contributed to this project and article equally. All authors read and approved the final manuscript.

\section{References}

1) Azetsop J. Social justice approach to road safety in Kenya: addressing the uneven distribution of road traffic injuries and deaths across population groups. Public health ethics. 2010;3(2):115-27.

2) FZamani-Alavijeh F, Niknami S, Bazargan M, Mohammadi E, Montazeri A, Ahmadi F, et al. Accidentrelated risk behaviors associated with motivations for motorcycle use in Iran: a country with very high 
traffic deaths. Traffic injury prevention. 2009;10(3):237-42. doi: 10.1080/15389580902822717. PMID: 19452365.

3) Fazel MR. Home-related injuries: do pay much attention to traffic accidents resulted in home-related injuries negligence? Archives of trauma research. 2012;1(4):143-4.

4) Barros AJ, Amaral RL, Oliveira MS, Lima SC, Goncalves EV. [Traffic accidents resulting in injuries: underreporting, characteristics, and case fatality rate]. Cadernos de saude publica. 2003;19(4):979-86. PMID:12973564

5) World report on road traffic injury prevention: summary, World Health Organization, Geneva. $2004 ; 1$-3.

6) Nja O, Nesvag SM. Traffic behaviour among adolescents using mopeds and light motorcycles. Journal of safety research. 2007;38(4):481-92. PMID: 17884435

7) Sharma BR. Road traffic injuries: a major global public health crisis. Public health. 2008;122(12):1399406. doi: 10.1016/j.puhe.2008.06.009. PMID: 18950819.

8) Wermert A, Opalek JM. A multidisciplinary motorcycle safety initiative. Journal of trauma nursing : the official journal of the Society of Trauma Nurses. 2009;16(4):208-13; quiz 14-5. doi: 10.1097/JTN.0b013e3181ca08d9. PMID: 20029285.

9) Kardamanidis K, Martiniuk A, Ivers RQ, Stevenson MR, Thistlethwaite K. Motorcycle rider training for the prevention of road traffic crashes. The Cochrane database of systematic reviews. 2010;6(10):CD005240. doi: 10.1002/14651858. PMID: 20927741.

10) World Health Organization, "Road safety", WHO road safety a public health issue, 2004. Available from: http://www.who.int/world-health-day/2004/infomaterials/world_report

11) WHO, Helmets: a road safety manual for decision-makers and practitioners, 2010-10-13. Available at: http://www.who.int/roadsafety/projects/manuals/helmet_manual/en/.

12) Afroz gh. Drivering Psychology, personality and aggressive Drivering. Tehran, Third Regional Conference on Traffic Management, NAJA, 2006.

13) Racioppi F, Eriksson L, Tingvall C, Villaveces A. Key messages from the WHO report. Preventing road traffic injury: a public health perspective for Europe. WHO Regional Office for Europe. 2004:1-5. Available from: http://www.euro.who.int

14) Mangus RS, Simons CJ, Jacobson LE, Streib EW, Gomez GA. Current helmet and protective equipment usage among previously injured ATV and motorcycle riders. Injury prevention. 2004;10(1):56-8. PMID: 14760029. PMCID: PMC1756539.

15) Naghavi M, Jafary N, Alaodini F, Akbari M. Epidemiology of Injury Related to External Cause in IRAN. Health Ministry, Tehran, 2004, Volume 1.

16) Trifiletti LB, Gielen AC, Sleet DA, Hopkins K. Behavioral and social sciences theories and models: are they used in unintentional injury prevention research? Health Education Research Advance. 2005; 20(3):298-307.

17) Evans D, Norman P. Predicting adolescent pedestrians' road-crossing intentions: an application and extension of the Theory of Planned Behaviour. Health education research. 2003;18(3):267-77. PMID: 12828229.

18) Handicap International Belgium and the Cambodian Red Cross. Cambodia Road Traffic Accident and Victim Information System Annual Report. 2004:7-10.

19) Bagheri P, Moshki M. A Different Approach to Traffic Accidents as the Main Cause of Trauma in Developing Countries. 2014.

20) Zamani-Alavijeh F, Niknami S, Mohammadi E, Montazeri A, Ghofranipour F, Ahmadi F, et al. Motorcyclists' reactions to safety helmet law: a qualitative study. BMC public health. 2009;20(9):393. PMID: 19843325. PMCID: PMC2770492.

21) Zargar M, Khaji A, Karbakhsh M. Pattern of motorcycle-related injuries in Tehran, 1999 to 2000: a study in 6 hospitals. Eastern Mediterranean health journal. 2006;12(1-2):81-7. PMID: 17037224.

22) Mazloomy MahmoodAbad S, Mehri A, Morovati SharifAbad M, Fallahzadeh H. Application of extended model of planned behavior in predicting helmet wearing among motorcyclist clerks in Yazd (2006). Journal of Birjand University of Medical Sciences. 2008; 14 (4):9-15.

23) Rolison JJ, Hewson PJ, Hellier E, Hurst L. Risks of high-powered motorcycles among younger adults. American journal of public health. 2013;103(3):568-71.

24) Schneider WHt, Savolainen PT, Van Boxel D, Beverley R. Examination of factors determining fault in two-vehicle motorcycle crashes. Accident; analysis and prevention. 2012;45:669-76 
25) Heydari ST, Lankarani KB, Vossoughi M, Javanmardi K, Sarikhani Y, Mahjoor K, et al. The prevalence and effective factors of crash helmet usage among motorcyclists in Iran. Journal of injury and violence research. 2015;8(1).

26) Bazargan-Hejazi S, Zamani-Alavijeh F, Hindman D, Mohamadi E, Bazargan M. How do motorcyclists manage mental tensions of risky riding? BMC public health. 2013;13:865

27) Amoran OE, Eme O, Giwa OA, Gbolahan OB. Road safety practices among commercial motorcyclists in a rural town in Nigeria: implications for health education. International quarterly of community health education. 2005;24(1):55-64

28) Zamani-Alavijeh F, Bazargan M, Shafiei A, Bazargan-Hejazi S. The frequency and predictors of helmet use among Iranian motorcyclists: A quantitative and qualitative study. Accident; analysis and prevention. 2011;43(4):1562-9.

29) Özkan T, Lajunen T, Chliaoutakis JE, Parker D, Summala H. Cross-cultural differences in driving behaviours: A comparison of six countries. Transportation research part F: traffic psychology and behaviour. 2006;9(3):227-42. 